\title{
Functional gains of including non-commercial epibenthic taxa in coastal beam trawl surveys: A note
}

\author{
Anik Brind'Amour ${ }^{\mathrm{a},{ }^{*}}$, Armelle Rouyer $^{\mathrm{a}}$ and Jocelyne Martin ${ }^{\mathrm{a}}$ \\ a IFREMER, Centre de Nantes, rue de l'île d'Yeu BP 21105, 44311 Nantes Cedex 03, France
}

*: Corresponding author : Brind'Amour A., Tel.: +33 02403741 60; fax : +33 02403740 75, email address : Anik.Brindamour@ifremer.fr

\begin{abstract}
:
The development of ecosystem-based indicators requires the broadening of a view of the community, from fish species to all the species (macrobenthic and fish) correctly captured by a given sampling gear. Many scientific surveys already have such integrated databases. The present note aims to demonstrate that existing databases, herein from dedicated coastal nursery surveys, are actually underexploited. Such databases contain information on non-commercial taxa, which could greatly improve our knowledge on the organisation and functioning of coastal ecosystems. Using two datasets, a "complete" dataset composed of commercial and not-commercial epibenthic trawled species (fish and invertebrate) and a "subset" dataset characterized by commercial and routinely surveyed species (mainly fish and cephalopods), different measures of functional diversity are compared to identify the functional gains of including epibenthic species. The results show that, when included in the analyses, epibenthic taxa provide gains of functional information, associated mainly with the community feeding traits, i.e. organisms composing the primary and secondary consumer levels of the coastal nursery food web. Failure to include some of the primary (zooplanktivores and suspension feeders) and secondary consumers (detritivores-scavengers) in coastal survey analyses may, for instance, hamper our understanding of energy flux between the benthic and water column compartments of these ecosystems. The results also suggest that the exclusion of some taxa associated with these two food web compartments, may lead to the underestimation of the functional redundancy in coastal ecosystems.
\end{abstract}

Keywords: Bay of Biscay; Beam trawl; Coastal surveys; Fish community; Functional diversity; Nursery grounds 

cephalopods).

\section{Introduction}

Recent integrated approaches, such as the Ecosystem Approach to Management, calls for sustainable and ecosystem-based indicators, that lead towards an understanding of how an ecosystem functions (Garcia and Cochrane 2005). These indicators require us to broaden our view of the studied communities, to include commercial as well as non-commercial species and fish as well as other taxa (e.g. molluscs, echinoderms). In certain ecosystems, such as the coastal system, indicators integrating both the structural (i.e. species composition) and functional attributes of the communities are increasingly recognized as useful tools to assess changes in these ecosystems (Costanza and Mageau 1999; Elliott and Quintino 2007; and Brind'Amour and Lobry (submitted)).

However, development of such ecosystem-based indicators require modification of the actual fishery surveys, in order to have community-extended program of data collection or, as in many bottom trawl fishery surveys, an enhanced use of the available databases. In many beam trawl surveys, such as the IBTS (International Beam Trawl Surveys), or coastal nurserydedicated surveys, these data already exist. Beam trawls are very effective in sampling vagile as well as epibenthic macrofauna and the latter may represent a large proportion (density or biomass) of the catches (Kaiser et al. 1994; Tillin et al. 2006).

It is within this context that the present Note aims to demonstrate that existing databases are underexploited, as they contain information on non-commercial taxa which could greatly improve our knowledge on the functioning of marine ecosystems. We have verified this hypothesis using data from coastal nursery surveys, divided in two datasets: a complete dataset, which included commercial and non-commercial taxa; and a subset dataset, which was composed of routinely-surveyed commercial taxa (i.e. mainly fish and 
1 Materials and Methods

2 Study area and sampling surveys

The study was undertaken in the Bay of Vilaine located along the French Atlantic

4 coast in southern Brittany (Fig. 1). The bay covers a $230 \mathrm{~km}^{2}$ surface area from the foreshore

5 to the $20 \mathrm{~m}$ isobath; it is characterized by an open shallow muddy estuarine area, under the

6 direct influence of freshwater inflows (Gilliers et al. 2006). Sampling was carried out from

7 the end of August to the end of October, between 2000 and 2005. Surveys were carried out

8 using a stratified sampling design, according to depth and sediment types. Depths ranged

9 from 5 to $35 \mathrm{~m}$ and, due to the sampling gear used in this study (i.e. beam trawl), the sediment

10 types ranged from coarse-grained sand and gravel to predominantly fine sand and/or coarse

11 silt. Sampling was undertaken using a $2.9 \mathrm{~m}$ wide and $0.5 \mathrm{~m}$ high beam trawl, with a $20-\mathrm{mm}$

12 stretched mesh net in the cod-end. A total of 195 hauls over the 6 years of sampling was

13 conducted, during the study. Each haul was carried out on sites displaying homogeneous

14 sediment and water depth and lasted 15 min, covering a mean surface of 4500 to $5000 \mathrm{~m}^{2}$.

\section{Species datasets}

All the individuals caught within a haul were identified at the species level (excluding the genus Liocarcinus and the Paguridae). Species were counted and the total biomass, per haul, was recorded. A total of 127 species was captured over the six-year surveys.

Considering the selectivity of the sampling gear, towards bentho-demersal species, only the species occurring in more than $5 \%$ of the sampling sites and displaying a relative density $\geq$ $5 \%$ of the total density were included in the analyses (i.e. 65 species). However, as this work was focused upon the functional aspects of the community, we selected species for which sufficient species-specific information was available; thus, finally , a total of 45 species were selected (Table 1). 
Estimation of the functional loss of information was assessed, by the comparison of

2 two datasets. The first dataset included the 45 aforementioned species and was herein defined

3 as the "complete" dataset. The second dataset was composed of 25 commercial and routinely

4 surveyed species, during nursery-dedicated cruises; it is defined further as the "subset" dataset

5 (Table 1).

\section{Species functional groups}

A functional description of the community was assessed, by categorizing the species into four functional guilds (Table 2). These guilds (feeding traits, ecological trait, mobility, and substrate preference) were selected because they are functionally significant, in structuring the coastal and estuarine nursery communities (Elliott and Dewailly 1995;

Bremner et al. 2003; and Franco et al. 2008). Therefore, a species-traits matrix was compiled using information gathered mainly from the literature (Elliott and Dewailly 1995; Raya et al. 1999; Laptikhovsky et al. 2002; Tillin et al. 2006; and Franco et al. 2008) and completed when necessary with the Marine Life Information Network (http://www.marlin.ac.uk) and Fishbase (Froese and Pauly 2006).

\section{Data analyses}

Since it is not possible (and somewhat undesirable) to assess the functional differences between communities using a single index of functional diversity, the comparison between the two datasets was realized using different measures of functional diversity. As each index has its own limits and advantages, their combination is likely to provide complementary information regarding the functional aspects of the community. Therefore, the assessment of the functional diversity was undertaken in three ways: (i) by the computation of a diversity index (Shannon diversity index) on the species densities, pooled by functional guilds; (ii) by cluster analyses, undertaken on the species-traits matrix; and (iii) by the computation of the functional richness index. Shannon diversity was calculated on species densities pooled by 
1 functional guilds. It was computed for each year, then averaged over the six-year surveys to

2 dampen out the annual variability.

Cluster analyses were conducted using Gower's dissimilarity coefficient on the standardized species-traits matrix (Podani and Schmera 2006). The dendrograms were produced by hierarchical clustering, using the Unweight Pair Group Method, with the Arithmetic Mean (UPGMA) method. The number of clusters was identified using the Calinski-Harabasz criterion, a pseudo $F$ (ANOVA) statistic which computes the sum of squared errors (distances) between the $\mathrm{k}^{\text {th }}$ cluster and the other $\mathrm{k}$ - 1 clusters; this is compared then to the internal sum of the squared errors, for the k clusters, i.e. taking their individual squared error terms and summing them (Calinski and Harabasz 1974; Milligan and Cooper 1985).

The index of functional richness (FRic), suggested recently by Villéger et al. (2008), was used to estimate and compare the volume occupied by the species, in the trait space for the two datasets. That index is computed following Cornwell et al. (2006); it estimates the convex hull volume (i.e. the smallest convex set, enclosing the points) using the Quickhull algorithm. The algorithm first identifies, then links the most extreme points (here, the species) and computes the volume inside. As this index is calculated from the species-traits matrix, it is influenced by the identity of the species and, more particularly, by the most dissimilar species in terms of functional traits (Villéger et al. 2008). The Quickhull algorithm requires continuous values in the species-traits matrix. Therefore, we transformed our presenceabsence species-matrix, into a "pseudo" species-traits matrix with continuous trait values. This was undertaken by calculating Jaccard's coefficient on the presence-absence traits matrix and by computing a Principal Coordinate Analysis (PCoA), on the Jaccard distance matrix

24 (Villéger et al. 2008). We verified that the structure of the original species-traits matrix was correlated with the pseudo species-traits matrix, using a Mantel correlation test between the 
1 Jaccard distance matrix calculated on the original data and an Euclidean distance matrix

2 calculated on the pseudo matrix. The correlations were, respectively, 0.978 and 0.987 for the

3 complete and the subset datasets.

Illustration of the functional richness was carried out by plotting a $3 \mathrm{D}$ graph of the first three axes of the Principal Component Analyses (PCA), calculated on the species-trait

6 matrices of each dataset. Cluster analyses and computations of the indices (diversity and

7 functional richness) were carried out using R software (Team 2008). Scripts from the S.

8 Villéger and available online (http://www.ecolag.univ-montp2.fr/software) were used to

9 compute the FRic. A 3D plot was undertaken using do3d, a wrapper for scatterplot3d

10 developed by A. Culhane in the made4 library.

11 Results and Discussion

$1^{\text {st }}$ and $2^{\text {nd }}$ consumers of the coastal food web

The Shannon diversity index computed on the (species densities pooled by) functional guilds indicated that the differences between the two datasets were controlled principally by the invertebrate taxa (Fig. 2). These differences were supported also by the taxonomic differences between the two datasets. For instance, invertebrate taxa accounted for nearly $10 \%$ of the total density in the complete dataset, whereas it represented over $70 \%$ in the subset dataset. Concurrently, the relative biomass displayed similar trends, with the invertebrate accounting for $51 \%$ of the total biomass in the complete dataset and $98 \%$ in the subset dataset.

Cluster analyses have confirmed the 'commonsense' expectations, that a greater number of functional traits were surveyed when all the trawled species ("complete" dataset) were included in the analyses. Four groups of traits were identified using the "complete" dataset, whereas only two groups were found using the "subset" dataset (Fig. 3). The two groups displayed by the "subset" dataset showed some similarities with two of the four 
1 groups of the "complete" dataset. The first group of traits that was identified commonly by

2 the two datasets was composed of omnivores and deposit feeders, seasonal migrants

3 preferring mixed and vegetal substrates (Group A, in Fig. 3). The second group included

4 marine juvenile migrants feeding on invertebrates (crustaceans and molluscs) or fish and

5 preferring fine substrates (Group B, in Fig. 3). That second group included also the phyto-

6 and zooplanktivores, in the "complete" dataset. The two other groups identified using the

7 "complete" dataset, but absent from the "subset" dataset were observed. These groups were

8 composed, respectively, of crawlers and detritivores, preferring mixed substrates (Group C, in

9 Fig. 3), and plankton-deposit feeders and burrowers, preferring fine sediment as substrate

10 (Group D, in Fig. 3).

11 Estimation of the FRic, i.e. the volume occupied by the species in the traits space,

12 indicated that the coastal community as defined with the complete data set $(F R i c=39.25)$ occupied 6.3 times more functional space, than the community characterized by the subset dataset $($ FRic $=6.20)$. When illustrated in the species-traits ordination (Fig. 4), the comparison between the two datasets has indicated that the feeding guilds composed of the planktivores and deposit feeders (PL, PD) were under-represented in the subset dataset (see the cloud of white points, at the front of Fig. 4).

Results from the cluster analyses, the computation and the graphical representation of the FRic, suggest that the functional loss of information was associated mainly with the feeding traits and, more precisely, with organisms composing the $1^{\text {st }}$ and $2^{\text {nd }}$ consumer levels

21 of the coastal nursery food web. Overlooking the primary (zooplanktivores and suspension feeders) and secondary consumers (detritivores-scavengers) in coastal and estuarine nursery habitats likely influences the understanding of that ecosystem functioning. For instance, most of the primary consumers are found on the bed of the estuary, where a rich benthic community develops (Mclusky and Elliott 2007). Although the trophic interaction between 
1 the bacteria-rich detritus and deposit feeders is considered as the dominant source of energy

2 in the estuary, zooplanktivores and suspension feeders also play an important role, in linking

3 the benthic and pelagic (water column) cycles (Baird and Ulanowicz 1993). Planktivores trap

4 nutrients and food particles, which are afterwards deposited partly as undigested material on

5 the bed, thereby supporting important densities of deposit feeders. However, the relative

6 contribution of the planktivores, to the overall productivity of estuaries, varies with the

7 turbidity conditions and water column dynamics of these ecosystems; it may represent

8 between $41-86 \%$ of the total biomass, in certain less-turbid ecosystems (Herman et al. 1999).

9 As for the detritivores and scavengers, they commonly constitute high biomasses in estuarine ecosystems. Being an important part of the detritus-benthic cycle, they interact (i.e. predation

11 and competition) with other $2^{\text {nd }}$ consumers and serve as food supply for $3^{\text {rd }}$ consumers, such 12 as large fish and birds (Mclusky and Elliott 2007).

\section{Functional redundancy}

The proximity and the overlap of the species (the white points, in Fig. 4) in the complete dataset, in comparison with the subset dataset suggest greater functional redundancy in the former dataset. For instance, the functional groups composed of detritivores-omnivores crawlers (DS, OM, CR) was characterized notably by epibenthic taxa, Ophiura ophiura, Asterias rubens, and Paguridae, absent from the subset dataset. Besides missing important components of the estuarine food web, these results suggest also that the exclusion of epibenthic fauna, in coastal analyses, may lead to an underestimation of the functional redundancy in these ecosystems. Redundancy is a desirable property of ecological communities, because it guaranties that specific ecosystem functions (e.g. nutrient trapping) will be maintained, in the case of species removal from that ecosystem (Micheli and Halpern 2005). In redundant communities, the disappearance of one or more species would not affect the ecosystem process, because species represent "redundant information" with respect to that 
1 process. Redundancy could be particularly important in coastal ecosystems, because these

2 communities are under multiple pressures (natural and anthropogenic) and the probability of

3 loosing vulnerable species and hence essential ecosystem functions, is likely to be high.

\section{Conclusions}

This study has addressed the question of what are the functional gains of including

6 epibenthic species in coastal nursery analyses? Classification analyses of the functional traits

7 showed that the addition of the epibenthic species, within the analyses, strengthens the

8 functional understanding of these ecosystems, notably by adding primary and secondary

9 consumers of the coastal food web. Thus exclusion of these species may lead to an

10 underestimation of the functional redundancy of these ecosystems.

\section{Acknowledgments}

This study was supported partly by the European programme IMAGE and the French

13 research agency (ANR), under the project AMPHORE. The authors are grateful to P.

14 Laffargue and J. Lobry for the map files of the Bay of Vilaine. They thank all the scientists

15 and crews of the R.V. Gwen Drez, who participated to the sampling cruises undertaken

16 between 2000 and 2005. Thank you to the anonymous reviewers who greatly enhanced this

17 Note with their comments and editorial suggestions. 


\section{References}

Baird, D., and R. E. Ulanowicz. 1993. Comparative study of the trophic structure, cycling and ecosystem properties of four tidal estuaries. Marine Ecology Progress Series 99: 221237.

Bremner, J., S. I. Rogers, and C. L. J. Frid. 2003. Assessing functional diversity in marine benthic ecosystems: a comparison of approaches. Marine Ecology Progress Series 254: 11-25.

Brind'amour, A., and J. Lobry. Submitted. Fish indicators in coastal-estuarine ecosystems: Main approaches along the French coasts. Aquatic Living Resources.

Calinski, T., and J. Harabasz. 1974. A Dendrite Method for Cluster Analysis. Communications in Statistics, 3: 1-27.

Cornwell, W. K., D. W. Schwilk, and D. D. Ackerly. 2006. A trait-based test for habitat filtering: Convex hull volume. Ecology 87: 1465-1471.

Costanza, R., and M. Mageau. 1999. What is a healthy ecosystem? Aquatic Ecology 33: 105115.

Elliott, M., and F. Dewailly. 1995. The structure and components of European estuarine fish assemblages. Netherlands Journal of Aquatic Ecology 29: 397-419.

Elliott, M., and V. Quintino. 2007. The Estuarine Quality Paradox, Environmental Homeostasis and the difficulty of detecting anthropogenic stress in naturally stressed areas. Marine Pollution Bulletin 54: 640-645.

Franco, A., M. Elliott, P. Franzoi, and P. Torricelli. 2008. Life strategy of fishes in European estuaries: the functional guild approach. Marine Ecology Progress Series 354: 219228.

Froese, R., and D. Pauly. 2006. FishBase, World Wide Web electronic publication. www.fishbase.org.

Garcia, S. M., and K. L. Cochrane. 2005. Ecosystem approach to fisheries: a review of implementation guidelines. ICES Journal of Marine Science 62: 311-318.

Gilliers, C., O. Le Pape, Y. Desaunay, J. Morin, D. Guérault, and R. Amara. 2006. Are growth and density quantitative indicators of essential fish habitat quality? An application to the common sole Solea solea nursery grounds. Estuarine Coastal and Shelf Science 69: 96-106. 
1 Herman, P. M. J., J. J. Middleburg, J. Van De Koppel, and C. H. R. Heip. 1999. Ecology of estuarine macrobenthos. Advances in Ecological Research 29: 195-240.

Isrs. 2004 Sustainable fisheries management in coral reef ecosystems, p. 14-27. International Society for Reef Studies.

Kaiser, M. J., S. I. Rogers, and D. T. Mccandless. 1994. Improving quantitative surveys of epibenthic communities using a modified $2 \mathrm{~m}$ beam trawl. Marine Ecology Progress Series 106: 131-138.

Laptikhovsky, V., A. Salman, B. Onsoy, and T. Katagan. 2002. Systematic position and reproduction of squid of the genera Alloteuthis (Cephalopda: Loliginidae) in the eastern Mediterranean. Journal of the Marine Biological Association of the UK 82: 983-985.

Mclusky, D. S., and M. Elliott. 2007. The estuarine ecosystem: ecology, threats and management, Third edition ed. Oxford University Press Inc.

Micheli, F., and B. S. Halpern. 2005. Low functional redundancy in coastal marine assemblages. Ecology Letters 8: 391-400.

Milligan, G. W., and M. C. Cooper. 1985. An examination of procedures for determining the number of clusters in a data set. Psychometrika 50: 159-179.

Podani, J., and D. Schmera. 2006. On dendrogram-based measures of functional diversity. Oikos 115: 179-185.

Raya, C. P., E. Balguerias, M. M. Fernandez-Nunez, and G. J. Pierce. 1999. On reproduction and age of the squid Loligo vulgaris from the Saharan Bank (north-west African coast). Journal of the Marine Biological Association of the UK 79: 111-120.

Team, R. D. C. 2008. R: A language and environment for statistical computing. R Foundation for Statistical Computing.

Tillin, H. M., J. G. Hiddink, S. Jennings, and M. J. Kaiser. 2006. Chronic bottom trawling alters the functional composition of benthic invertebrate communities on a sea-basin scale. Marine Ecology Progress Series 318: 31-45.

Villéger, S., N. Mason, and D. Mouillot. 2008. New multidimensional functional diversity indices for a multifaceted framework in functional ecology. Ecology 89: 2290-2301. 


\section{Figure captions}

2

3 Fig. 1. Bathymetric map of the bay of Vilaine located in northern bay of Biscay (France).

4 Fig. 2. Shannon diversity index calculated on functional guilds for the "complete" and

5 "subset" datasets. Values represent species densities pooled by functional guilds.

6 Fig. 3. Classification analyses conducted on the "complete" and "subset" datasets using the

722 traits classified in four functional groups. Trait codes are described in Table 2. Letters

8 indicate the clusters identified by the Calinski-Harabasz criterion (see Material and Methods

9 section for details)

10 Fig. 4. 3D graph of the principal axes calculated on the species-trait matrices for each dataset.

11 Functional traits were added on each axis to facilitate the interpretation. They were positioned 12 according to their scores (i.e. eigenvalues). 


\section{$1 \quad$ Tables}

2 Table 1 List of the species included in the computation of the three functional indices.

3 The "complete" dataset was composed of all the species in the table $(n=45)$ whereas the

4 "subset" dataset included the species marked by an asterisk $(n=25)$.

Species

Alloteuthis

Acrocnida brachiata

Amphiura filiformis

Aphrodita aculeata

Arnoglossus laterna

Asterias rubens

Buglossidium luteum

Callionymus lyra

Carcinus maenas

Cerastoderma edule

Chelidonichthys gurnardus

Chelidonichthys lucernus

Subset

Ciliata mustela

Crangon crangon

Dicentrarchus labrax

Dicologlossa cuneata

Gobius niger

Hippocampus hippocampus

Liocarcinus

Loligo vulgaris

Merlangius merlangus

Merluccius merluccius

Mullus surmuletus

Necora puber

Ophiura ophiura

Owenia fusiformis 
Brind' Amour et al.

Paguridae

Palaemon serratus

Pectinaria koreni

Philine aperta

Phrynorhombus norvegicus

Platichthys flesus

Pleuronectes platessa

*

Pomatoschistus minutus

Psammechinus miliaris

Raja clavata

Scyliorhinus canicula

Sepia officinalis

Solea solea

*

Sparus auratus

Spondyliosoma cantharus

Trisopterus luscus

Trisopterus minutus

Turritella communis 
1 Table 2 Functional traits classified in four functional guilds. The guilds were chosen

2 after Elliott and Dewailly (1995).

\begin{tabular}{|c|c|c|}
\hline Functional guild & Trait & Code \\
\hline \multirow[t]{9}{*}{ Feeding } & Planktivores (zoo and/or phyto) & PL \\
\hline & Invertebrates (mollusks, crustaceans) & IS \\
\hline & Fish & FS \\
\hline & Fish + Invertebrates & IF \\
\hline & Plants & VS \\
\hline & Deposit feeders & DSS \\
\hline & Planktivores + Deposit feeders & $\mathrm{PD}$ \\
\hline & Detritivores-scavengers & DS \\
\hline & Omnivores (fish, invertebrate, plants) & $\mathrm{OM}$ \\
\hline \multirow[t]{4}{*}{ Ecological } & Marine migrant (appears irregularly in the estuary) & MA \\
\hline & Marine seasonal migrant & MS \\
\hline & $\begin{array}{l}\text { Marine juvenile migrant (marine juveniles using estuary as nursery } \\
\text { grounds) }\end{array}$ & MJ \\
\hline & Estuarine resident (entire life in the estuary) & ER \\
\hline \multirow[t]{4}{*}{ Mobility } & Swimmer & SR \\
\hline & Crawler & $\mathrm{CR}$ \\
\hline & Burrower & $\mathrm{BR}$ \\
\hline & Permanent attachment & PA \\
\hline \multirow[t]{5}{*}{ Substrate preference } & Sandy bottom (sand exclusively) & $\mathrm{S}$ \\
\hline & Soft bottom (sand, mud, fine gravel) & $\mathrm{F}$ \\
\hline & Rough bottom (rock, stone, pebble) & $\mathrm{R}$ \\
\hline & Mixed or various (no apparent preferences) & M \\
\hline & Vegetation (seeweeds) & Veg \\
\hline
\end{tabular}


Fig. 1

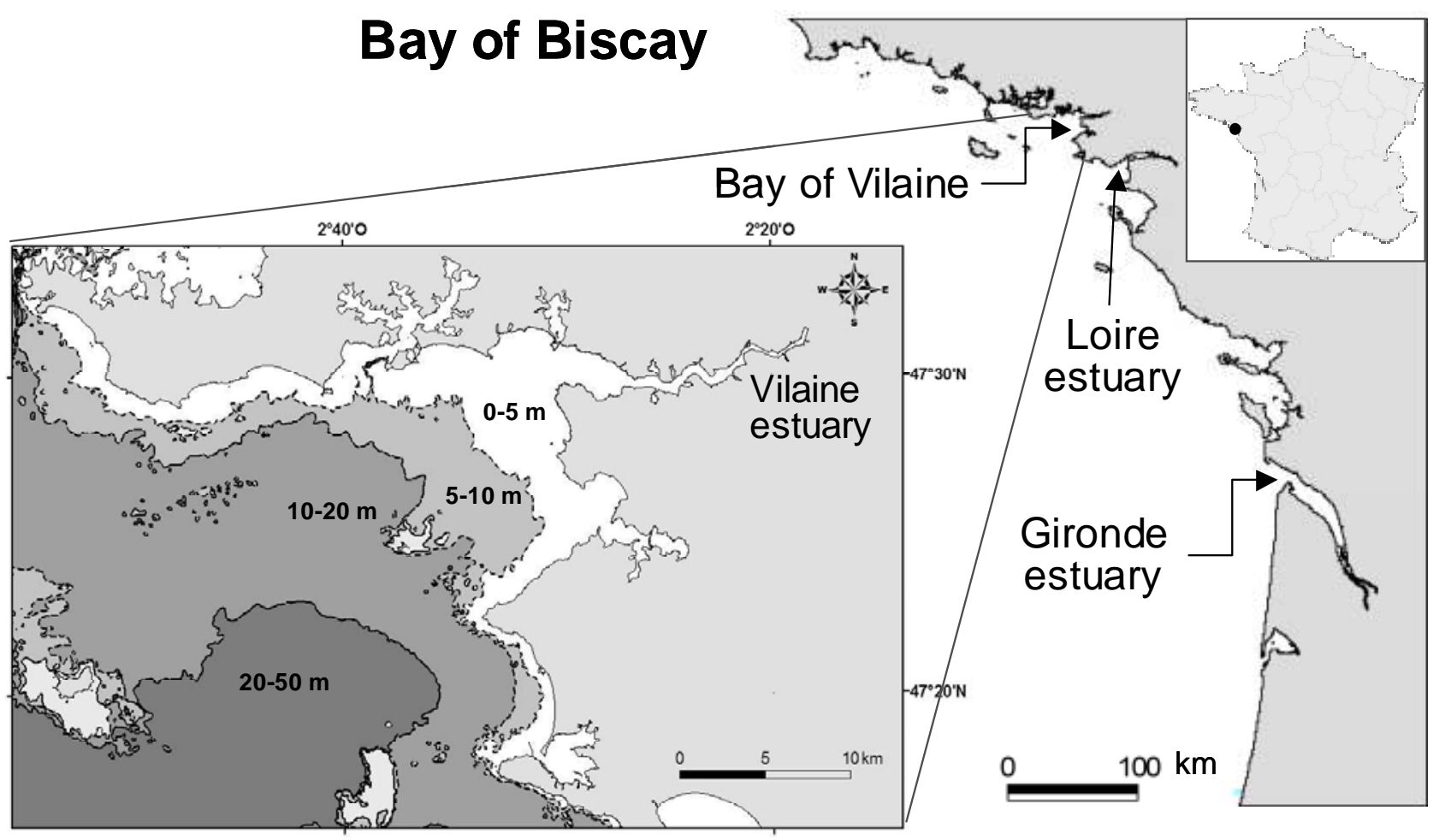


Fig. 2

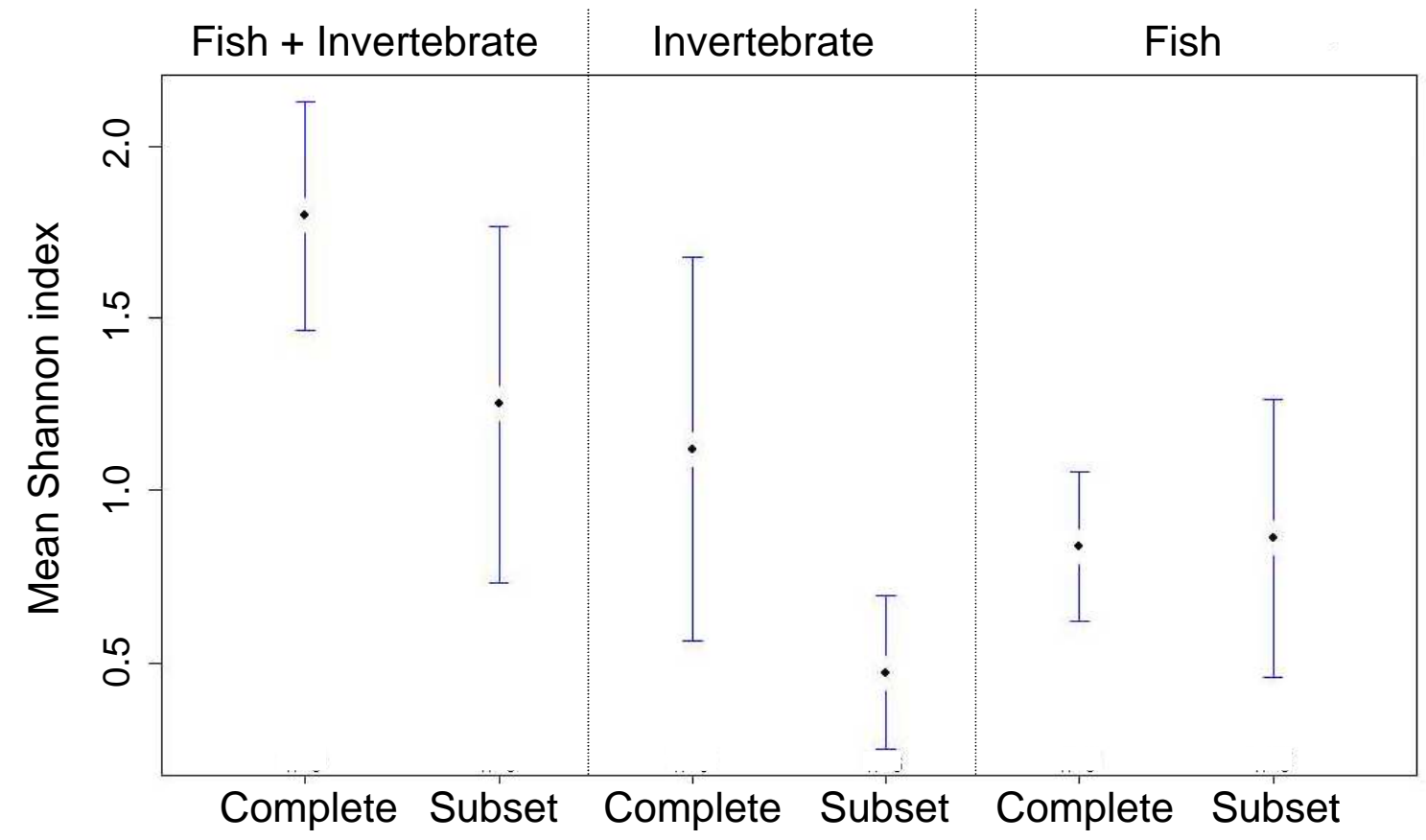


Fig. 3

Complete

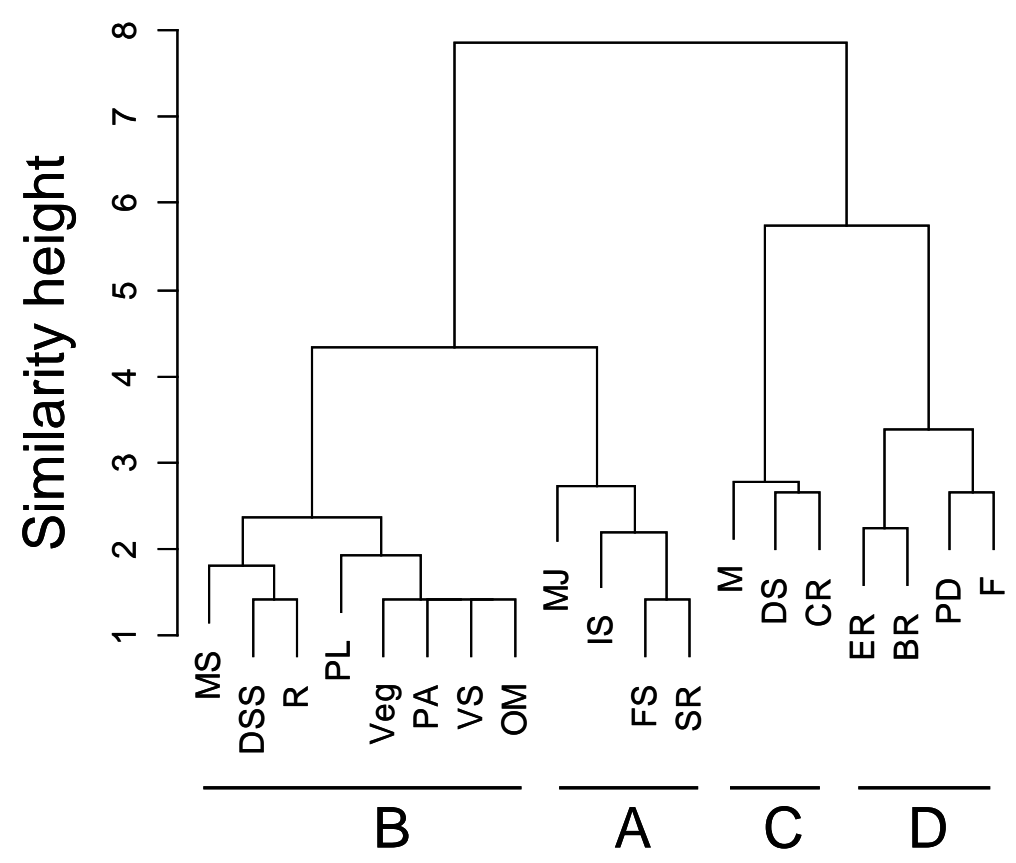

Subset

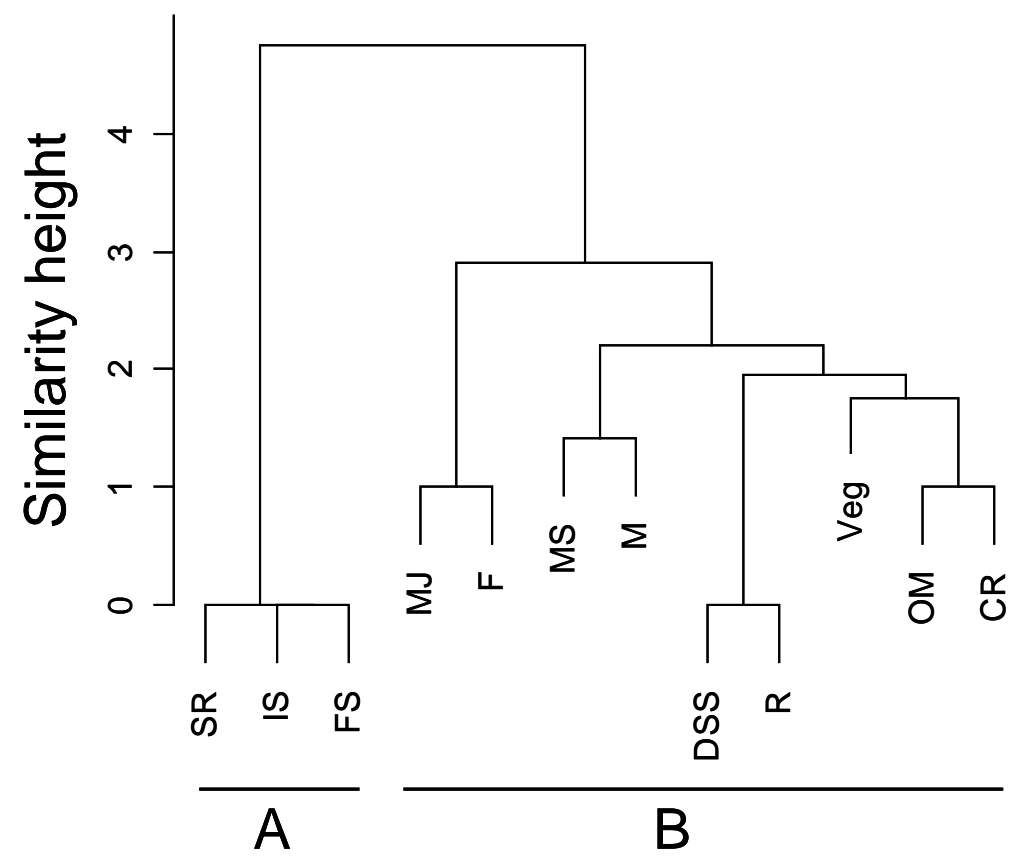


Fig. 4

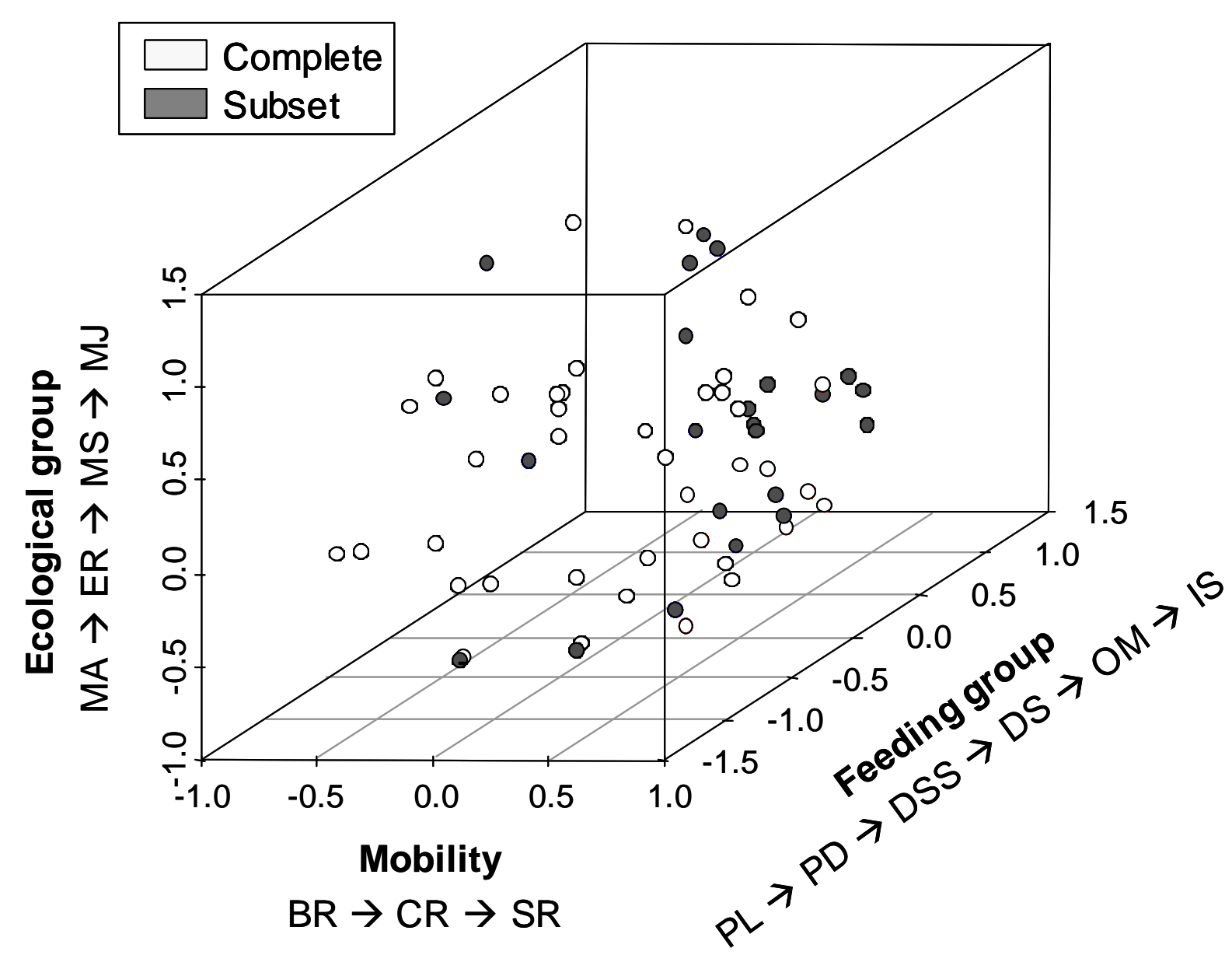

